\title{
Metaphysics of Change and Continuity: Exactly what is changing and what gets continued?
}

\section{Soraj HONGLADAROM}

\begin{abstract}
This is a metaphysical and conceptual analysis of the concepts 'change' and 'continuity'. The Buddhists are in agreement with Heraclitus that all are flowing and nothing remains. However, the Buddhists have a much more elaborate theory about change and continuity, and this theory is a key element in the entire Buddhist system of related doctrines, viz., that of karma and rebirth, the possibility of Liberation (nirvāna) and others. Simply put, the Buddhist emphasizes that change is there in every aspect of reality.
\end{abstract}

According to a later developed form of the Buddhist teaching, change is absolutely pervasive, and even these particles are subject to change as they are nothing more than putative objects which are conceptualized to be such and such, and without the conceptualization they are 'nothing' at all. (This is known as the Doctrine of Emptiness). Hence it seems that continuity is not possible. But in fact according to the later theory, change is not only possible, it is accepted as part and parcel of everyday life. The fact that nothing at all remains the same does not imply that continuity is not possible, since continuity does not always have to be that of an inherently existing object. A changing object can be continued also, in roughly the same sense as we say that an event, like a drama, continues even though everything in it is changing. The thread that ties the disparate elements of the event together in this case lies within our own conceptual imputation. This does not imply that everything is subjective, since the distinction between subject and object presupposes the idea of an absolutely existing individual self, which all Buddhist schools rejects. So in this later theory, absolute change is not possible because there is, ultimately speaking nothing to change, and when there is no change there is no continuation either. This is not to deny the empirical fact of changes and continuities that are present to us; things are there and they are indeed changing. What is being denied here is the belief that that there are essences to things which endure through all the changes. Since things are empty (of inherently existing nature) they can change, and continuity is only possible, not because there is something that exists and endures, but because there is change. A drama that does not move cannot be continued.

The foregoing discussions of the Buddhist theories have many implications for the dialog between science and religion. One point is that science still seems to subscribe to the object/ subject distinction. But if change and continuity are not real in the ultimate sense, then perhaps the distinction should be reconsidered. Another point concerns how to find continuity amidst all the change. But perhaps in some important sense continuity depends on us.

Key Words: Metaphysics, change, continuity, Buddhist philosophy, essence

Hongladarom, Soraj, (2015) "Metaphysics of Change and Continuity: Exactly what is changing and what gets continued?", Kilikya Felsefe Dergisi, (2) pp. 41-60. 


\section{Introduction}

Change and continuity are the topics that have been discussed and debated for as long as there is philosophy. As with other basic concepts, change and continuity are necessary for our understanding, indeed our making sense of the world around us. Without the concepts of change and continuity, we would not be able to understand how discrete events are tied up together in such a way that they create a coherent story that makes sense of our surrounding, our situation, our bodies, our identities.

In this paper we look at the metaphysics of change and continuity from a Buddhist perspective. The Buddhists are in agreement with Heraclitus that all are flowing and nothing remains. However, the Buddhists have a much more elaborate theory about change and continuity, and this theory is a key element in the entire Buddhist system of related doctrines, viz., that of karma and rebirth, the possibility of Liberation (nirvāna) and others. Simply put, the Buddhist emphasizes that change is there in every aspect of reality.

An earlier Buddhist theory, the Abhidharma, has it that all perceptible reality is composed of minute 'thought-moments' and 'though-instants' (cittakhana) which form the basic building blocks of reality. The idea is very much like that of modern science. However, the Abhidharmists hold that these minute particles are unchanging and have no particular characteristics. And here they are more like Democritus than modern science. Having no properties of their own, they mix up with one another in varying patterns so that the results are seen to be, say, a table of this particular color or a flower of this particular smell. Change and continuity are nothing but these particles forming patterns among themselves and later becoming dissolved and forming other patterns. The change from a table to a heap of ashes is nothing but these rearrangements of the basic particles, which themselves are unchanging. Here one sees that there is an objective continuity-the particles themselves do not change.

According to a later developed form of the Buddhist teaching, however, change is absolutely pervasive, and even these particles are subject to change as they are nothing more than putative objects which are conceptualized to be such and such, and without the conceptualization they are 'nothing' at all. (This is known as the Doctrine of Emptiness). Hence it seems that continuity is not possible. But in fact according to the later theory, change is not only possible, it is accepted as part and parcel of everyday life. The fact that nothing at all remains 
the same does not imply that continuity is not possible, since continuity does not always have to be that of an inherently existing object. A changing object can be continued also, in roughly the same sense as we say that an event, like a drama, continues even though everything in it is changing. The thread that ties the disparate elements of the event together in this case lies within our own conceptual imputation. This does not imply that everything is subjective, since the distinction between subject and object presupposes the idea of an absolutely existing individual self, which all Buddhist schools rejects. So in this later theory, absolute change is not possible because there is, ultimately speaking nothing to change, and when there is no change there is no continuation either. This is not to deny the empirical fact of changes and continuities that are present to us; things are there and they are indeed changing. What is being denied here is the belief that that there are essences to things which endure through all the changes. Since things are empty (of inherently existing nature) they can change, and continuity is only possible, not because there is something that exists and endures, but because there is change. A drama that does not move cannot be continued.

These accounts of the Buddhist schools are supplemented by the thought of the Japanese philosopher Nishida Kitarō. According to Kitarō, Aristotle's logical system prevalent in the West has a serious flaw in that it fails to account satisfactorily to the lived experience of change and continuity. This is because Aristotelian logic centers around the notion of the subject. Kitarō's answer to this predicament is to base the center of the logical system to the predicate rather than the subject. It is Kitarō's "logic of predicate" that is apparently able to solve the dilemma arising from the Aristotelian one. And we shall also see that Kitarō's thoughts are intimately bound up with that of the Māhāyana Buddhism, especially Nāgārjuna's analysis of change and continuity.

So what is in fact changing? According to the Abhidharma, nothing at all, because ultimate reality consists in the basic particles of thought-moments as discussed above. But according to the Māhāyanists, everything does change. The doctrine of emptiness states that nothing whatsoever remains the same in the sense that they retain their material identity, and these Abhidharmic basic thoughtmoments are not excepted. And what is continued? For the Abhidharma, of course, it is these thought-moments, and for the Māhāyanists, nothing continues in the sense that it is false that there is something that retains its material identity even for a shortest period of time. This seems to be an internecine dispute of different Buddhist schools, but as I shall make clear in the paper, this has a far reaching 
consequence in our understanding of the concepts of change and continuity and their relevance in contemporary situation.

The foregoing discussion of the Buddhist theories has many implications for the dialog between science and religion. One point is that science still seems to subscribe to the object/subject distinction. But if change and continuity are not real in the ultimate sense, then perhaps the distinction should be reconsidered. Another point concerns how to find continuity amidst all the change. But perhaps in some important sense continuity depends on $u s$.

In what follows I shall elaborate on the Abhidharma and the Māhāyana on these issues, and then we will have a discussion on these issues as a key toward a dialog and perhaps a synergy between Buddhism and science.

\section{The Abhidharmic Theory of Change and Continuity}

A basic view of reality according to the Abhidharma is that the reality is divided into four major kinds, viz. consciousness (citta), mental states (cetasika), matter (rüpa) and nirvāna. Consciousness is described as the 'aware factor' that when present in us makes us someone who knows and thinks. Mental states are manifestations of consciousness and they can be divided and subdivided further according the different kinds of emotions or modifications of consciousness. Matter is what constitutes the material reality and is what things like mountains or stars are composed of. The last kind of basic reality is the most difficult to describe, because it is simply not mentioned in the vocabulary of science, and is something unique to Buddhism. nirvāna is the state of Liberation from all sufferings, and in the Abhidharma nirvāna is categorized as a basic kind of ultimate reality. In the Abhidhamattha Sanghaha, nirvāna (or nibbāna in Pali) is described as "Nibbāna is an objective state which is deathless, absolutely endless, non-conditioned, and incomparable." The idea is that nirvāna is completely different from mundane reality, which itself consists of mental and physical phenomena. Nirvāna is completely different because both the mental and physical phenomena are subject to change; they are always conditioned by various factors and are always caused. They do not last and are insubstantial in that they do not have any kind of essence that would make them what they are in objective reality. By contrast nirvāna is

${ }^{1}$ Bhadanta Anuruddhācariya, A Manual of Abhidhamma being Abhidhammattha Sanghaha, Nārada Mahā Thera transl., 4th Ed. revised. (Kuala Lumpur: Buddhist Missionary Society, 1979), p. 354. 
none of these, and hence the Abhidharma masters classified nirvāna as a basic kind of reality. This is rather surprising because such a categorization seems to lead one to believe that nirvāna itself is part of objective reality, and is of a different kind of thing altogether from the mental and physical phenomena that make up the first three kinds. This will be an issue that the Māhāyanist, through the Doctrine of Emptiness which will be discussed later, will take up.

The Abhidharma is consistent in analyzing the first three types of reality to be constantly changing and composed of very minute particles called rūpa-kālapa. All kinds of matter (there are 28 kinds in all, but to enumerate all in this paper would be quite tedious) are produced by four kinds of cause that come in groups of very tiny particles, or kaläpas. According to Mehm Tin Mon, ${ }^{2}$ these have four main features:

1. All the rūpas in a kalāpa arise together; i.e., they have a common genesis.

2. They also cease or dissolve together; i.e., they have a common cessation.

3. They all depend on the four great essentials present in the kalāpa for their arising; i.e., they have a common dependence.

4. They are so thoroughly mixed that they cannot be distinguished; i.e., they co-exist.

Mehm Tin Mon also notes further that "kalāpas are so small that they are invisible even under electronic microscope. The size of a kaläpa in the human realm is just a $10^{-5}$ of a paramānu, which is smaller than an atom. So kalāpas are comparable to electrons, protons and neutrons in size." ${ }^{3}$

It should be clear that what he is getting at is that the Abhidharma states that physical and mental phenomena are constituted by tiny groups of causes and conditions. For example, in the case of the eye there are as many as ten conditions working together as its cause. These are the eight 'inseparable qualities'

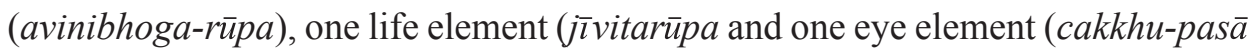
$d a$ ). The eight inseparable mental qualities consist of earth, water, fire, air, color, smell, taste and nutritive essence (oja) are bound together, and when these eight

\footnotetext{
${ }^{2}$ Mehm Tin Mon, Buddha Abhidhamma: Ultimate Science (Penang: Sukhi Hotu Sdn Bhd, 2002), p. 247.

${ }^{3}$ Mehm Tin Mon, Buddha Abhidhamma, p. 248.
} 
basic elements are added the eye element (what is there in the eye that makes it function as an eye) and the life element then what results is the 'eye-decad', which is nothing more than the functioning, living eye. And the eye-decad here is just one kind of kalāpas, there being 21 kinds in all. ${ }^{4}$ So one can see that even one kal appa consists of a number of yet smaller elements.

Here one sees the methodology of the Abhidharma in analyzing phenomena into smaller components. The purpose, of course, is to aid the meditating mind in the quest for Liberation. When the Dharma practitioner sees that the eye itself is composed of so many small elements, he or she is then released from the attachment in the eye and what it sees. Understanding that a functioning eye is nothing but a repository of various separate elements, the practitioner then realizes that the eye itself is nothing; there is just no thing in the world that is an eye apart from the fact that various elements and particles are working together in one very particular way such that there emerges the eye. There is no 'essence' to the eye such that it defines this collection of various elements forever as an eye. The eight inseparable elements are present in many other organs, and the eye element itself (cakkhu-pas $\bar{a} d a$ ) is only a result of yet further working of other elements concerning lights and electrochemical compounds that result from light falling on the retina. These elements by themselves are not the eye-essence either, for they still depend on many other factors for their functioning.

The foregoing is an analysis for a rather complicated object, namely the eye, but what about ordinary, everyday inanimate object, like a stone or a table? The Abhidharma says that each object is composed of numerous smaller objects, the most basic of which is very tiny. In the Abhidharmattha Sanghaha, there is a description of all material qualities (lakkhanarūpa) in terms of material productivity, continuity, decay and impermanence. Material productivity is also known as arising; continuity as abiding; decay as ceasing, and impermanence as the overall characteristic of all material phenomenon which are subject to the earlier three characteristics. All Buddhist schools concur that all physical and mental phenomena are subject to these four characteristics, and in the text we find the following explanation of the term lakkhanarūpa:

The life-term of conditioned rūpa is normally 17 thought-moments or 51 minor thought-instants. The first though-moment is like the upacaya, the last thoughtmoment is like the aniccata, the intermediate 15 are like the jarata. Aniccata is the dissolution of rūpa.

${ }^{4}$ Mehm Tin Mon, Buddha Abhidhamma, p. 248. 
Strictly speaking, there are only three lakkhana-rūpa, viz: birth, growth-decay, and death. Aniccata is synonymous with marana (death). The entire interval between birth and death constitutes decay or development.

With the exception of the five rūpas-namely, two viññattis, jati, jara, and aniccata, all the remaining 23 rūpas last for 17 thought-moments. ${ }^{5}$

Never mind the rather excessive details in the quote above, the basic picture is that all physical phenomena are subject to arising, abiding and ceasing, and they do so at a tremendously fast speed. It is explained at billions of 'thought-moments' are there in only one flash of lightning. ${ }^{6}$ Hence, supposed that a flash of lightning is around one hundredth of a second in duration, a thought-moment is at least one hundred billionth of a second, and this is only a very conservative estimate because a lightning flash may be shorter and there may be much more than one billion though-moments in one flash. Here the accurate number of the duration is inconsequential; the main point is that a physical phenomenon is composed of very tiny events or instants and hence one can find no substance behind any such phenomenon. It is stated in the text above that a conditioned rūpa last for exactly 17 thought-moments, and each thought-moment can even be further subdivided into three 'thought-instants'. Thus the duration of a conditioned rūpa is equal to 51 "minor thought-instants". One might wonder how the author(s) of these Abhidhammic text knew exactly how many thought-moments or thought-instants there are in a conditioned ruppa, and the standard answer is that this was taught by the Buddha himself, who, being omniscient, knew exactly what he taught. The Buddha (or anyone who was the author of the Abhidharma) engaged in deep meditation beyond the power of ordinary human beings, and immediately 'saw' these thought-instants and other things. However, we actually do not need to speculate on the epistemology of the Abhidharma here, ${ }^{7}$ it is more important to note that, no matter how short each thought-moment is, it is still something that can be counted and identified, and hence has duration. This will be taken up by the Māhāyanist critics, as we shall see later on.

\footnotetext{
${ }^{5}$ Anuruddhacariya, Abhidhammattha Sanghaha, p. 334.

${ }^{6}$ Anuruddhacariya, Abhidhammattha Sanghaha, p. 334.

${ }^{7}$ There are a number of Buddhist texts and scholars dealing with this issue. See, for example, Dharmak̄̄rti's epistemology in John Dunne, Foundations of Dharmakīrti's Philosophy (Boston: Wisdom Publications, 2004).
} 
These characteristics of material qualities also point to the fact that change and continuity occur at a very rapid rate in a physical phenomenon. Change is right there in the very nature of a material thing. This of course is in accordance with the findings of modern physics. A material object, such as a table, is composed of very tiny atomic particles, each of which is in turn composed of many more subatomic particles and at this level it is quite hard to distinguish which is an event, which is an individual thing, which is matter and which is energy.

The Abhidharmic worldview, then, is a step further from the commonsensical view that ordinary human beings take to be an accurate description of reality. One should bear in mind that main purpose of presenting such a finely detailed picture of the material qualities is for the realization of the ultimate goal of Buddhism, which is release from samsāra and finding permanent salvation in nirvāna, which cannot be attained if the practitioner still does not know the exact nature of reality as something that is always subject to arising, abiding and ceasing. What these three characteristics of impermanence are thoroughly analyzed, it is found that a thing that previously might be thought to contain an essence is in fact insubstantial. No essence can be found. What separates two material objects from each other, for example, the mug on my table and the table itself, is not that these two things are by their very nature separate and distinct from each other, but merely because we impute our conceptual apparatus on them that way. According to the Abhidharmic picture that we have seen, the mug and the table are nothing but collection of a tremendously vast numbers of thought-moments, which are collected in kal àpas. These things are so short in duration that billions of them can fit in but one flash of lightning. The purpose of this picture is not the same as in modern science, which latter aims at presenting an accurate picture of objective reality; the picture of the Abhidharma is rather more like an aid to the practice of realizing the impermanence and insubstantiality of all things, which is an important step toward becoming released from sufferings.

As for change and continuity, then, the picture that emerges from the Abhidharma is that change seems to be all pervasive; each thought-moment and thought-instant does not necessarily connect with one another. As they are very short in duration and are juxtaposed to one another, change is analyzed as just this juxtaposition. There is then change, but perhaps at the expense of continuity. Everything is subject to arising, abiding and ceasing, and thus is subject to change. However, these thought-moments or thought-instants themselves are not subject to change according to the Abhidharma. There is an analysis of ordinary macro- 
objects such as mugs and tables. But the text does not mention how these thoughtmoments or thought-instants are to be analyzed. The presupposition seems to be that these are basic and cannot be further analyzed and subdivided. Thus if one is intent on finding continuity in the Abhidharmic picture, it is these thoughtmoments and thought-instants individually that do continue. Of course nothing in the world does remain the same, but according to the Abhidharma these thoughtmoments and -instants do remain the same, and it is only their composition and dissolution in various forms that account for the production, existence and decay of material things.

The idea of continuity seems to presuppose that there be something that remains, which functions as the subject of change. It is this subject that continues and provides for a basis by which the change is that of a same thing, hence there is continuity. In the Abhidharma, it is clear that all material and mental entities do change and do so by virtue of the arrangements and rearrangements of thoughtmoments and thought-instants. At one level, then, there is no enduring thing at all, no selfsame entity that persists through any change. But at the deeper level, there is material, psycho-physical and objective continuity. This deeper level, on the other hand, are not available for ordinary perception, and it is only the high level practitioners who could perceive them directly (reference). It is only through perception tinged by ignorance that leads one to believe that there is really an existent, enduring object before one, such as a coffee mug.

\section{Nishida Kitarō and Zeno's Paradox}

An interesting account of the problem of continuity and change is given by Japanese philosopher Nishida Kitarō. ${ }^{8}$ The problem is demonstrated in Zeno's paradox of motion. Observing an arrow that has been shot from the bow, one can't coherently assert that an arrow is actually moving, according to Zeno, because the arrow needs to be at a certain place at each point of time, which by definition cannot contain any duration at all. But if this is the case, then the arrow is not moving because all of its trajectories consist of a series of these moments and at each moment it is not moving. So if it is not moving at one moment, then it is not moving at all. The argument is valid and has baffled logicians ever since. The saliency of the problem lies in the fact that this valid argument purports to show that our normal perception of everyday reality is wrong. The arrow is actually not

\footnotetext{
${ }^{8}$ Jiang, Tao, "The Problematic of Continuity: Nishida Kitarō and Aristotle" Philosophy East
} and West 55.3(July 2005): 447-460. 
moving, even though we see that it is moving toward the target. There are two choices. Either we have to accept that our everyday perception is wrong and we have been deceived all the time, or we need to find a way to explain the paradox.

According to Aristotelian logic, which is the one system accepted in the West, there is the problem how to account for both change and continuity together. Kitaro calls the Aristotelian a "logic of subject", because its locus is on the subject as opposed to the predicate of the statement. This accords with the Aristotelian notion of individual substance as something that has properties but itself is not the same as the properties. Individual substances function as subjects of statements and the properties work as their properties. A key Aristotelian schema of a descriptive statement which is capable of bearing truth value is "a is F" where ' $a$ ' stands for an object, an individual substance functioning subject of the statement, and ' $F$ ' stands for the property that a has. Hence in the Zeno case the object of investigation is then the statement "The arrow is moving". The focus is on the arrow itself, and the question is whether it is moving or not. According to Zeno, it is not moving at all as we have seen.

However, attending to Zeno's argument, one finds a real difficulty of not being able to account for the apparent fact that the arrow is indeed moving. If at any instant of time the arrow is at rest, then it is at rest throughout, there being no one particular instant where it is moving. One cannot solve the problem by pointing out that such points of time do not exist. One might, for example, argue against Zeno that points of time containing no duration at all do not actually exist and what do exist are only chunks of time which contain a length of time however small. Hence there is not such a thing as a point in the line of time, and what does exist exist in the line are smaller sections of the line which can be divided and further divided, but no absolute point can be reached. The arrow, then, moves in these smaller chunks of time, and since these chunks are not points the arrow can move within those chunks. This argument does not seem to work, however, because one would then need to find an account of how the arrow moves from the beginning of the chunk to the end. Supposed there is a small chunk (and we imagine it to be very small indeed), $\mathrm{C}$, since $\mathrm{C}$ is a chunk and not a point there must be a moment at which $\mathrm{C}$ begins and another later moment at which $\mathrm{C}$ ends. This is always the case no matter how small $\mathrm{C}$ is. To say that these starting and ending points do not exist would contradict our understanding of $\mathrm{C}$ being a chunk in the first place, for being a chunk just means that the starting and ending points must be different. If this is the case, then accounting for the arrow moving within 
chunk $\mathrm{C}$ is not different from accounting for its movement in the bigger chunk of time from the bow to the target.

The problem that Aristotelian logic has with Zeno's paradox is precisely that of finding an account that does justice both to change and continuity at the same time. In the case of the arrow, as long as it is assumed that it is the same arrow that is moving toward its target, then the difficulty arises. For how could one account for the arrow's moving from point $\mathrm{A}$ in time to point $\mathrm{B}$, there being an infinite number of points lying between A and B? One way to solve the movement problem is to assume that movement in nature is similar to movement in a movie. That is, movement consists of a series of changes in position at particular moments in time and when these series are strung together there emerges the continuous movement. Let's call this the 'cinematographic theory'. In this theory the movement is always disjointed because the arrow would need to 'jump' from one film in the movie to another, adjacent one. A consequence is that there is no thing that stays the same from one cinematographic film to another; hence in order to preserve change, continuity has to be compromised. On the other hand, if one were to preserve continuity, if one, that is, would want to maintain that the arrow that moves is the same one throughout, then one would find oneself at an impasse because in order for the arrow to be absolutely the same, it cannot move because once it moves, it moves from one cinematographic film to another with nothing that remains as before.

According to Nishida, this is precisely where the problem with Aristotelian logic lies. It cannot account for the existence of both continuity and change in the case of the moving arrow. Either the arrow does not move at all, which is contradictory to perception, or it does not remain the same, which is also contradictory. Nishida's way out is to argue that the root cause of the problem is with Aristotelian logic itself, namely its presupposition that the center of attention is the logical subject. So long as it is presupposed that there is the logical subject, attention is then fixed on whether it, in this case the arrow which is either moving or not, has or does not have certain properties. According to Nishida this logical subject is always an abstract one since it is supposed to lack all properties, functioning only as a core that possess the properties. So long as the logical subject is presupposed, there is always the problem of how to account for its change or continuity. Nishida's way out is to propose the 'logic of predicate'; instead of assuming that the basic block of reality is the individual substance, Nishida argues that it is the properties that function as predicates in logical statements. According 
to the logic of predicate, the moving arrow is accounted for by presupposing that the moving is what ultimately exists in this case, and then the arrow does move because it is an instantiation of the moving, the arrow itself having to independent existence (reference). On the other hand, the arrow also can be said to be at rest at each moment of time, as Zeno argued. This is so because there is the predicate of 'being at rest', which is instantiated by the arrow. Hence according to Nishida's logic of predicate, the arrow can both be at rest and be moving at the same time. This contradiction, however, is not possible in Aristotelian logic.

The upshot is that, in Nishida's logic of predicate, change and continuity are entirely possible, and I would like to argue that this is the only way in which the two concepts are possible. At each moment, the arrow is both moving and at rest. This is possible because the arrow itself, as the subject, does not have an independent existence apart from its properties. Thus there is no self subsisting thing to possess contradictory properties in this case; what is there are two different contexts - that of an arrow staying at same at a time instant, and an arrow moving toward its target, and it is in reference to these contexts that the arrow is said to be either at rest or moving. Change and continuity, then, is configured not as properties of self subsisting or independently existing individual objects, but as part and parcel of contexts of discourse (called bāsho in Japanese) in which they stand in a web of semantic relations to other concepts in the same context.

\section{Nāgārjuna: Change and Continuity in Māhāyana Buddhism}

Nishida's account of change and continuity and his critique of Aristotelian logic is much influenced by Māhāyana Buddhism. In fact it could be said that his account does not diverge at all from the thoughts of Nāgārjuna, the Buddhist saint who lived in the 2nd century A.D. in southern India. In Nāgārjuna's most famous work, The Fundamental Verses of the Middle Way (Mūlamadhayamakak $\bar{a} r i k \bar{a}),{ }^{9}$ he outlines teaching on emptiness (sūnyatā), which is the fundamental teaching of Māhāyana Buddhism. The similarities between Nishida's and Nāgā rjuna's account of change and continuity are that both accept that the two concepts are dependent upon human cognition. For Nishida, it is our perception of smooth change and continuity in the cinematographic movement of things that is in fact responsible for there being movement and continuity. And this is the same for $\mathrm{N}$ āgārjuna. However, Nāgārjuna goes one step further. For Nāgārjuna movement is

${ }^{9}$ Nāgārjuna, The Fundamental Verses of the Middle Way: Nāgārjuna's Mūlamadhyamakakārikā, Jay L. Garfield transl. (Oxford University Press, 1995). 
empty; that is to say, there is no inherent existence to movement, or by extension change as well as continuity. To say that change and continuity are empty is just to say that they lack inherent existence such that they do not exist independently of other things, and that they owe their existence in an important way as referents to conceptual thought.

According to Nāgārjuna, to say that motion (or change and continuity) is nonempty would entail many absurd consequences. Commenting on Chapter II of the Mūlamadhayamakakārikā, Jay Garfield has the following to say:

Nāgārjuna argues that from such a view [that motion is nonempty] a number of absurd consequences would follow: Things not now in motion, but which were in motion in the past or which will be in the future, would have to undergo substantial change, effectively becoming different things when they change state from motion to rest or vice versa; a regress would ensue from the need for the entity motion itself to be in motion; motion would occur in the absence of moving things; the moment at which a thing begins or ceases motion would be indescribable. Nāg arjuna concludes that a reification of motion is incoherent. Motion is therefore empty. ${ }^{10}$

Applying Nāgārjuna's argument here to Zeno's paradox of the moving arrow, one finds that for Nāgārjuna, the arrow neither moves, nor is at rest, nor both moves and is at rest, nor neither moves nor is at rest. This is so because, for it to be moving, it has to be identifiable through time, which we have seen from Nishida's discussion not to be the case. But we can't say that it is at rest either, for that would starkly contradict ordinary perception. However, the third option is not available either because it contradicts itself, and the fourth option is also untenable because there is in this context just nothing else that the arrow does except for moving or being at rest. Nāgarrjuna denies all these four possibilities (termed 'negative tetralemma') because all of them result from the presupposition that there is an arrow as an individually self subsisting thing, whose property (whether being at rest or moving) is the subject of investigation. So long as the arrow is presumed to be an inherently existing thing in itself, there will be these problems. His way out, famously, is to claim that the arrow itself is empty. Not only that, but the property of motion itself is also empty, as summarized by Garfield in the quote above.

We can then see that Nāgarjuna's seems to be a logical consequence of Nishida's theory of logic of predicate. Nishida allows for statements of the form

${ }^{10} \mathrm{~N} \bar{a} \mathrm{~g} \bar{a} \mathrm{rjuna}$, The Fundamental Verses, pp. 124-125. 
"a is $\mathrm{F}$ and a is not F", arguing that this does not violate basic logical principle because otherwise Zeno's paradox would not be solvable. Nāgārjuna, on the other hand, not only accepts the form to be possible, but also accepts statements of the form "Neither a is F nor a is not F" and "it is not the case that neither a is F nor a is not F" too. The idea of the positive and negative tetralemma is that all statements of the form

$a$ is $F$

a is not $F$

Both a is $\mathrm{F}$ and $\mathrm{a}$ is not $\mathrm{F}$

Neither a is $\mathrm{F}$ nor a is not $\mathrm{F}$

are tenable ('positive tetralemma') and untenable ('negative tetralemma') at the same time. This apparent paradox and outright contradiction is explained by showing that the tenability of all the components of the tetralemma works because there is a presupposition of the existence of the logical subject, ' $a$ ' in this case. So long as a is considered to be 'empty' of inherent existence or essential characteristics which would fix its own identity comes what may, then it does not make the same sense as in the more familiar Aristotelian logic to say that a is or is not $\mathrm{F}$, or any other horns of the tetralemma. The arrow, in this case, would be both moving, at rest, both moving and at rest, neither moving nor at rest, and none of these at the same time. Without there being the arrow as the fixed logical subject, anything seems to follow.

The following two verses contains Nāgārjuna's view of change and motion, which has a far reaching implication toward what we are discussing in this paper:

Motion does not begin in what has moved,

Nor does it begin in what has not moved,

Nor does it begin in what is moving,

In what, then, does motion begin?

Prior to the beginning of motion,

There is no beginning of motion in

The going or in the gone.

How could there be motion in the not-gone?

(MMK II: 12-13). ${ }^{11}$

${ }^{11}$ Nāgārjuna, The Fundamental Verses, pp. 7-8. 
In the first verse, the idea is that motion does not begin anywhere, hence it is empty and any attempt to impute motion to things is always an act of conscious, conceptual imputation without objective basis in reality. (this does not mean that no motion exists in 'objective' identifiable reality - doctrine of two truths). Motion does not begin in what has moved because a thing that has moved would presumably be now at rest, so does not have any motion, or it is moving, in that case motion does not begin there because it is moving by virtue of having been moved in the past, and hence motion obviously did not begin at that particular moment of presently moving. It does not begin in what has not moved, because things that are at rest necessarily do not have motion. But motion is not in things that are moving either, because it is moving and must have been moved earlier. Hence motion is not in the going, nor in the gone, and certainly not in the notgone.

But does this entail that nothing is moving at all? Is Nāgārjuna a philosopher of the same stripe as Zeno, who pursues arguments to the effect that the world as we know it is not possible at all? Being a Buddhist, Nāgārjuna cannot accept that nothing is changing, because that would be opposite to one of the most basic teachings of all schools of Buddhism. But at the same time we also see in the verses above that motion does not begin anywhere. The second verse shows that the beginning of motion in things that are moving and have already moved seems to arise from nowhere, there being nothing in motion prior to it. The idea is that there must be a definite beginning of motion in things that are moving and have already moved. But where exactly is that beginning? Prior to the beginning the moving or the moved is not that at all, and if one were to assume that the moving or the moved have essential characteristics of moving, then one would be at loss to explain how such things could arise in the first place. If this applies to the moving and the moved, then the case of the not-gone would of course be easy because there is no motion there at all. Nāgārjuna's conclusion from these difficult verses is that if one takes motion to be an essential property of things which are taken to be inherently existing, then one finds this problem of not being able to find motion in them. This is strikingly reminiscent of Zeno. Hence, one might conclude that paradoxes like Zeno's arise because of a misconception of ultimate reality. When one mistakenly believes that there are such things as arrows that are taken to possess essential characteristics (arrowness, for example), one finds oneself mired in the paradox. For Nāgārjuna, the way out of the paradox would be to realize that the arrow itself is empty of any essential characteristics. Not only that, but the movement of the arrow is empty too. 
Nāgārjuna clearly states his position in the following verse:

Neither an entity nor a nonentity

Moves in any of the three ways.

So motion, mover,

And route are nonexistent.

(MMK II: 25) ${ }^{12}$

The 'three ways' here refer to past, present and future. That no thing moves in any of the three ways would then mean that it does not move in the past, present or future. Both an entity and a nonentity (such as the unicorn) do not move at all. This is also Zeno's conclusion. All the mover, motion and route are nonexistent because, since there is no motion, there is necessarily no mover or route taken. All things exist in the past, present and the future, but if they existed in the past, they could not be said to contain any movement because the past moments have already passed away and exist now only in memory. They could not be said to exist in the future either because the future has yet to come to existence. So the only possibility for changing things to exist in at the present, but as Zeno has demonstrated the present itself is nothing but a point of time, an instant in the timeline with no duration, so changing things in fact do not change at the present moment for the same reason. Hence there is no change.

But, as with Zeno's paradox, that there is no change is so contradictory to our understanding of the world that we just cannot accept it at face value. Nishida, as we have seen, explains the fact of change in his logic of predicate, pointing out that the basis of reality should be the logical predicate rather than the logical subject. For Nāganrjuna, the way out is the realization that there are two levels of understanding the world. At the conventional level, there is of course change, and things are always changing all the time. This is the level of ordinary understanding and perception, together with conceptualization and language use. At the deeper, ultimate level, however, things are not what they seem, and it is at this level that Nāgārjuna's analysis shows that there is actually no change in any thing and at any time. The picture is not that of the ultimate reality lying there as the basis and the conventional is merely 'what appears'. That would be to denigrate the conventional truth, with the consequence that the Buddha's own teachings, conveyed in normal language, would be taken to be merely conventional hence having to real force. The issue here is very complicated, and would obviously take too much time and space than available for this paper. Suffice it to say here that

${ }^{12}$ Nāgārjuna, The Fundamental Verses, p. 9. 
for Nāgārjuna, change is indeed possible at the conventional level, which does not mean that it is merely conventional and hence merely apparent. But a correct understanding of the Buddha's teaching also necessarily relies on an understanding of the ultimate level, the level of emptiness, wherein there is no change as we have just discussed. Perhaps a way toward a reconciliation of these two truths would be for one to recognize that the conventional level of reality is as real as it gets, but still its reality does depend on language and concepts, and as such they open a way toward a realization of the same reality without language and concepts, reality as emptiness. Understanding things this way, change and continuity would then be concepts lying on the conventional side of things. The point is that these two concepts are not written in stones; they are but our tools in dealing with the world around us, both conceptually and physically. But in themselves they do not have inherent existence such that we could grasp them as ultimately real.

\section{Continuity and Change: Buddhism and Science}

So what are the consequences of all this for the discussion on Buddhism and science? If change and continuity are, strictly speaking, not there in objective reality, then these key concepts, which are relied on extensively in science, would point toward science itself as something of a construct. This does not mean that science itself loses all its objectivity and its status as the paradigm of knowledge in today's world. But it does mean that we should always be aware that science, or scientific knowledge, is composed of concepts and as the concepts of change and continuity lie at a very deep level of scientific analysis and understanding, and as both concepts are, according to Buddhism, only parts and parcel of conventional, and not ultimate, reality, science itself is part of conventional reality too. What this does mean is that there is no such thing as absolute objectivity such that there is an absolute connection between concepts and reality. After all concepts are our own tools that we use to carve out whatever it is 'out there' so that we make sense of it. The lesson for science would then be that we should stop thinking of science as an enterprise that drives toward an eventual complete correspondence between understanding and reality. Of course this is not new at all, and many historians and philosophers of science have long pointed this out. What is my point in this essay is simply that this has not been new for more than two thousand years, since Buddhism has indicated this for a long time.

This, however, must not be taken to mean that there is no objectivity in science. Those who believe that if scientific knowledge is found to be composed 
of concepts, like 'change' and 'continuity', whose meanings are not there in outside reality then nothing is objective at all are firmly convinced that there is an all-or-nothing dilemma between something being absolutely objective and something absolutely subjective. That is, these persons believe in the dichotomy between the object and the subject. Since science, they argue, belongs to the realm of the object, to say that science is composed of concepts whose meanings are constructed would mean that they are not objective, which for them mean the concepts are purely subjective and arbitrary. But in Buddhism it is precisely this dichotomy between the subject and the object that is suspect, for the dichotomy presupposes the existence of a self which is found to be actually non-existent. The distinction between subject and object exists because it is supposed that there is a self, the one who thinks, which stands in contrast with what is thought about, or the object. But if the subject is nothing but a series of juxtaposing mental episodes, with nothing substantially and inherently existing that binds them together, then the whole foundation of the dichotomy breaks down. Of course this does not mean that in Buddhism there is absolutely no conception of the self; what it does mean, on the contrary, is that any conception of a self is a construction, in quite the same way as the notions of change and continuity are constructed out of the ineffable reality. Only that this 'ineffable' reality is in an important sense one and the same with the empirical reality we are all familiar with. The point is that, if one accepts that the dichotomy between the subject and the object is itself a construction, something that is not inherently there but arises as a consequence of our dealing with the world, then one would be less worried about science losing its supposed 'objectivity' if their concepts are found to be merely labels.

Through the Abhidharma, we have learned that change and continuity somehow have their basis in reality outside of our own conceptualization. Hence the Abhidharma maintains a realist position. Even though such a basis consists of very tiny particles, these particles do not change and the apparent changes that are perceptible to our eyes are only apparent, since in fact these change are nothing more or less than arrangements and rearrangements of these tiny particles. However, one can certainly carry on the analysis further, and Zeno's paradox shows that it is mathematically possible to divide duration in time and distance in space further and further with no end, and a consequence is that change is in fact not possible at all. If we would like to uphold our intuition and argue that change does in fact exist, we would do so only through rethinking of Zeno-type paradoxes, and one way to do this is through Nishida's critique of Aristotelian logic. The analysis is carried on to the furthest extent in Nāgārjuna's Doctrine of Emptiness, 
which states that nothing whatsoever is real in the sense of existing substantially and inherently without any intervention by the perceiver. In this sense, nothing is real, in the Abhidharmic sense of the tiny particles themselves being real. Even the Abhidharmic particles are themselves consequences of conceptualization of reality. Without any words to name those particles, it does not quite make a lot of sense to say that they exist, because it does not make much sense even to talk about them in the first place. This is also the case with concepts such as 'change' and 'continuity'.

So what have we learned? As the analysis of space and time can indeed be carried out with consciousness and the sense of the 'I', Buddhism has found that self-consciousness is in fact an illusion, a simulacrum. In the same way as continuity is assembled out of disparate, juxtaposing physical episodes, the sense of an 'I' is also assembled out of disparate episodes in the always changing thoughts of a person. This, of course, does not mean that the person does not exist, for if she did not exist, who would be responsible for action? And the whole ethical edifice of Buddhism would break apart. In the same vein, continuity does exist through the changing physical episodes, for the episodes are conceptualized and labeled in such a way that there is something that 'carries over' through the episodes. Likewise, the sense of the self is also conceptualized in the same way. What this points to is that the dichotomy of subject and object, on which modern science bases itself (as in the separation between the observer and the phenomenon, etc.), is not quite tenable. It is only as tenable as it needs to be, such as when one needs to found a system of knowledge, such as modern science, on a kind of shared certainty. But Buddhism teaches us that this is in fact something constructed, that the distinction between subject and object is not based on reality per se. Reconsidering the epistemic basis of science in this way might help us realize that science is an ongoing phenomenon and nothing is settled. And that the dialog between science and religion such as Buddhism has a lot of substance left that should be carried on further.

Soraj Hongladarom, Chulalongkorn University, Department of Philosophy, Bangkok, Thailand 


\section{REFERENCES}

Bhadanta Anuruddhācariya. A Manual of Abhidhamma being Abhidhammattha Sanghaha. Nārada Mahā Thera transl., 4th Ed. revised. Kuala Lumpur: Buddhist Missionary Society, 1979.

Dunne, John. Foundations of Dharmakīrti's Philosophy. Boston: Wisdom Publications, 2004.

Jiang, Tao. "The Problematic of Continuity: Nishida Kitarō's and Aristotle." Philosophy East and West 55.3(July 2005): 447-460.

Mon, Mehm Tin. Buddha Abhidhamma: Ultimate Science. Penang: Sukhi Hotu Sdn Bhd, 2002. 